\title{
Reply to the Letter by Dr. Antonio Ponzetto Regarding "The Role of History of Gastro-Duodenal Ulcer in Patients with Upper Gastrointestinal Bleeding"
}

\author{
Yusaku Takatori $^{\mathrm{a}}$ Motohiko Kato $^{\mathrm{b}}$ \\ ${ }^{a}$ Department of Gastroenterology, National Hospital Organization, Saitama Hospital, Saitama, Japan; \\ ${ }^{b}$ Division of Research and Development for Minimally Invasive Treatment, Cancer Center, Keio University \\ School of Medicine, Tokyo, Japan
}

Thank you for a letter about our recent study. It has been known that the infection of Helicobacter pylori is a risk factor for causing gastro-duodenal ulcer (GDU) and that its eradication can decrease the recurrence of GDU [1]. However, it is controversial whether all patients should undergo $H$. pylori tests and eradication with some reasons. First, elderly patients may not need $H$. pylori tests and eradication because of mortality caused by the presence of other diseases. Second, eradication of $H$. pylori has some adverse event (e.g., renal dysfunction, Clostridium difficile colitis and dementia). Third, there is a concern on the increase of medical care costs for administering eradication therapy.

As the population ages, increasing medical care cost is becoming a social burden,

\section{References}

1 Asaka M, Kato M, Sugiyama T, Satoh $\mathrm{K}, \mathrm{Ku}$ wayama H, Fukuda Y, Fujioka T, Takemoto T, Kimura K, Shimoyama T, Shimizu K, Kobayashi S: Follow-up survey of a large-scale multicenter, double-blind study of triple therapy with lansoprazole, amoxicillin, and clarithromycin for eradication of Helicobacter especially in developed countries. Despite improvements in the standard of health care, upper gastrointestinal bleeding (UGIB) is still a life-threatening disease, which sometimes requires intensive care, and it has a settled impact for medical care cost. Therefore, physicians should attend to prevent the onset or recurrence of UGIB also from the point of view of medical economy. According to our data, the history of GDU is an important risk factor to decide the necessity of endoscopic intervention in patients with UGIB [2]. Therefore, we thought that patients with GDU that needed endoscopic intervention should undergo $H$. pylori tests. This kind of prevention of GDU for appropriate cases would lead to reduction of medical care cost in UGIB. pylori in Japanese peptic ulcer patients. J Gastroenterol 2003;38:339-347.

2 Takatori Y, Kato M, Sunata Y, Hirai Y, Kubosawa Y, Abe K, Takada Y, Hirata T, Banno S, Wada M, Kinoshita S, Mori H, Takabayashi K, Kikuchi M, Kikuchi M, Suzuki M, Uraoka $\mathrm{T}$ : The role of history of gastro-duodenal ulcer
As described above, the accurate diagnosis for $H$. pylori infection is required, considering the cost-effective aspect. Japanese guidelines of $H$. pylori infection recommended that physicians diagnose the infection of $H$. pylori using results of multitests with appreciation about property of each test [3]. As you mentioned, a flexible response would contribute to the improvement of diagnostic yield of $H$. pylori and reduction of medical care cost in UGIB patients in your country.

\section{Disclosure Statement}

We have no financial conflicts of interest to disclose concerning this manuscript.

\section{KARGER}

(c) 2018 S. Karger AG, Basel
Yusaku Takatori

35, Shinanomachi

Shinjuku-ku

160-8582 Tokyo (Japan)

E-Mail moto28hiko@icloud.com in patients with upper gastrointestinal bleeding. Dig Dis 2018;36:177-181.

3 Asaka M, Satoh K, Sugano K, Sugiyama T, Takahashi S, Fukuda Y, Ota H, Murakami K, Kimura K, Shimoyama T: Guidelines in the management of Helicobacter pylori infection in Japan. Helicobacter 2001;6:177-186. 